\title{
Response of Southern Ocean Convection and Abyssal Overturning to Surface Buoyancy Perturbations
}

\author{
AdELE K. MORRISON \\ Research School of Earth Sciences, and ARC Centre of Excellence for Climate System Science, \\ Australian National University, Canberra, Australian Capital Territory, Australia \\ MATTHEW H. ENGLAND \\ Climate Change Research Centre, and ARC Centre of Excellence for Climate System Science, \\ University of New South Wales, Sydney, New South Wales, Australia \\ ANDREW MCC. HOGG \\ Research School of Earth Sciences, and ARC Centre of Excellence for Climate System Science, \\ Australian National University, Canberra, Australian Capital Territory, Australia
}

(Manuscript received 5 February 2014, in final form 1 March 2015)

\begin{abstract}
This study explores how buoyancy-driven modulations in the abyssal overturning circulation affect Southern Ocean temperature and salinity in an eddy-permitting ocean model. Consistent with previous studies, the modeled surface ocean south of $50^{\circ} \mathrm{S}$ cools and freshens in response to enhanced surface freshwater fluxes. Paradoxically, upper-ocean cooling also occurs for small increases in the surface relaxation temperature. In both cases, the surface cooling and freshening trends are linked to reduced convection and a slowing of the abyssal overturning circulation, with associated changes in oceanic transport of heat and salt. For small perturbations, convective shutdown does not begin immediately, but instead develops via a slow feedback between the weakened overturning circulation and buoyancy anomalies. Two distinct phases of surface cooling are found: an initial smaller trend associated with the advective (overturning) adjustment of up to $\sim 60 \mathrm{yr}$, followed by more rapid surface cooling during the convective shutdown period. The duration of the first advective phase decreases for larger forcing perturbations. As may be expected during the convective shutdown phase, the deep ocean warms and salinifies for both types of buoyancy perturbation. However, during the advective phase, the deep ocean freshens in response to freshwater perturbations but salinifies in the surface warming perturbations. The magnitudes of the modeled surface and abyssal trends during the advective phase are comparable to the recent observed multidecadal Southern Ocean temperature and salinity changes.
\end{abstract}

\section{Introduction}

Broad-scale patterns in high-latitude Southern Ocean temperature and salinity trends have emerged in the observations over recent decades. Despite warming atmospheric temperature and enhanced heat flux entering the upper ocean, the sea surface temperature (SST) south of $50^{\circ} \mathrm{S}$ has cooled (Bintanja et al. 2013; Latif et al.

Corresponding author address: Adele Morrison, Program in Atmospheric and Oceanic Sciences, Princeton University, 300 Forrestal Rd., Princeton, NJ 08544

E-mail: adelem@princeton.edu
2013). Durack and Wijffels (2010) have shown freshening of the sea surface salinity (SSS) extending across the same region. In contrast, in the abyssal Southern Ocean a warming trend is evident across nearly all ocean basins (Purkey and Johnson 2010). The extent to which these changes have been caused directly by altered surface fluxes or through a feedback of ocean circulation changes is unclear.

One obvious possible mechanism for driving surface cooling and freshening simultaneously with deep ocean warming is through a modulation of the abyssal overturning circulation and the associated vertical ocean heat flux. The lower oceanic overturning cell is fed by 
the production of Antarctic Bottom Water (AABW) on the continental shelves around Antarctica, through a process which entrains fresher, ambient waters into the dense shelf waters cascading down from sea ice formation regions and ice shelves. AABW spreads northward to fill the bottom of the world's oceans, gradually mixing into the lighter overlying waters, and completing the meridional overturning loop by upwelling in the Southern Ocean as warmer and saltier Circumpolar Deep Water. A decrease in the abyssal overturning circulation would therefore reduce the transport of heat and salt to the surface region where the lower cell outcrops around Antarctica. By analogy with the more familiar case of North Atlantic Deep Water shutdown (e.g., Manabe and Stouffer 1995), a slower rate of AABW formation would result in a cooling of the sea surface temperature south of around $50^{\circ} \mathrm{S}$ in the Southern Ocean because of the reduced upward heat flux. In the Southern Hemisphere case, the cooling would also be accompanied by a strong freshening of the sea surface salinity because of the higher salinity of the upwelling water masses compared with the relatively fresher AABW.

Present observational uncertainties are too large to conclude if the AABW transport or formation rates have changed in line with the recent abyssal temperature and salinity trends. Some studies present evidence that the transport has decreased over recent decades (Shimada et al. 2012; Sloyan et al. 2013; Huhn et al. 2013). However, others argue for alternative explanations of the abyssal temperature and salinity trends, such as changes in water mass properties at formation sites (van Wijk and Rintoul 2014), increased entrainment (Couldrey et al. 2013), or a rebound response from the 1970s Weddell Polynya (Latif et al. 2013). The increasing trend in the southern annular mode could also be contributing to surface cooling and freshening (e.g., Thompson et al. 2011). Because of the wide range of possible drivers, our aim in this study is not to attribute recent Southern Ocean temperature and salinity trends to changes in the abyssal overturning cell transport. Rather, we aim to improve understanding of the potential magnitude and time scale of the temperature and salinity changes that could arise from buoyancy-driven modulations of AABW transport.

A number of coarse-resolution, coupled GCM experiments have previously shown surface cooling and deep warming linked to a reduction in the rate of Southern Ocean bottom water formation, driven either by increased freshwater fluxes (e.g., Stouffer et al. 2007; Aiken and England 2008; Swingedouw et al. 2009; Menviel et al. 2010; Kirkman and Bitz 2011; Bintanja et al. 2013) or natural centennial variability (Galbraith et al. 2011; Martin et al. 2013; Latif et al. 2013). In response to a slowdown of the abyssal overturning transport, these models show surface cooling and freshening, an increase in sea ice extent, and deep warming. However, there is disagreement between different studies regarding the processes that control the magnitude of the surface cooling: Swingedouw et al. (2009) found that the magnitude of cooling increases with the rate of freshwater input, while Menviel et al. (2010) have shown that a smaller freshwater perturbation results in a larger surface cooling. Given the paleooceanographic context of most of these studies, there has also been little attention paid to the rate of the temperature and salinity changes that result from the overturning slowdown.

Here, we present a process study investigating the ocean dynamics and resultant temperature and salinity anomalies associated with decreasing Southern Ocean bottom water formation in an eddy-permitting, idealized ocean model. Through the analysis of a wide range of surface freshwater and heat flux perturbations, we explore the dynamical ocean control on the time scale and magnitude of the modeled changes in temperature and salinity. In contrast to previous studies, we find that there are two distinct time scales for the temperature and salinity changes. The initial slower response, which is caused by a reduction in advection, is followed by a more rapid convective shutdown. Surface cooling and abyssal warming occur during both periods but are largest once convection begins to slow. This fast response may be delayed by $\sim 60$ years in the case of small forcing perturbations.

\section{Numerical model}

We investigate the response to an imposed change in Southern Ocean surface buoyancy forcing in a series of perturbation experiments using the MITgcm (Marshall et al. 1997) in an idealized, pole-to-pole, ocean sector configuration with an eddy-permitting resolution of $1 / 4^{\circ}$. The reference case is the same as that described in Hogg et al. (2013), but with a longer spin-up period of $2500 \mathrm{yr}$. The domain is a $40^{\circ}$ longitudinal sector of ocean, extending from $70^{\circ} \mathrm{S}$ to $70^{\circ} \mathrm{N}$, with a simple Drake Passagelike sill of depth $1800 \mathrm{~m}$ (Fig. 1a). There are 36 vertical levels, with resolution increasing toward the surface. We use the model in hydrostatic, Boussinesq mode and with no explicit eddy parameterization scheme. Horizontal and vertical viscosity-diffusion are minimized with a biharmonic lateral viscosity-diffusivity of $10^{11} \mathrm{~m}^{4} \mathrm{~s}^{-1}$ and a vertical viscosity-diffusivity of $10^{-5} \mathrm{~m}^{2} \mathrm{~s}^{-1}$. The vertical diffusivity is amplified by a factor of 200 near the surface to generate mixed layers of an appropriate depth and is also enhanced to enable convective adjustment of unstable density profiles. The model uses a linear 

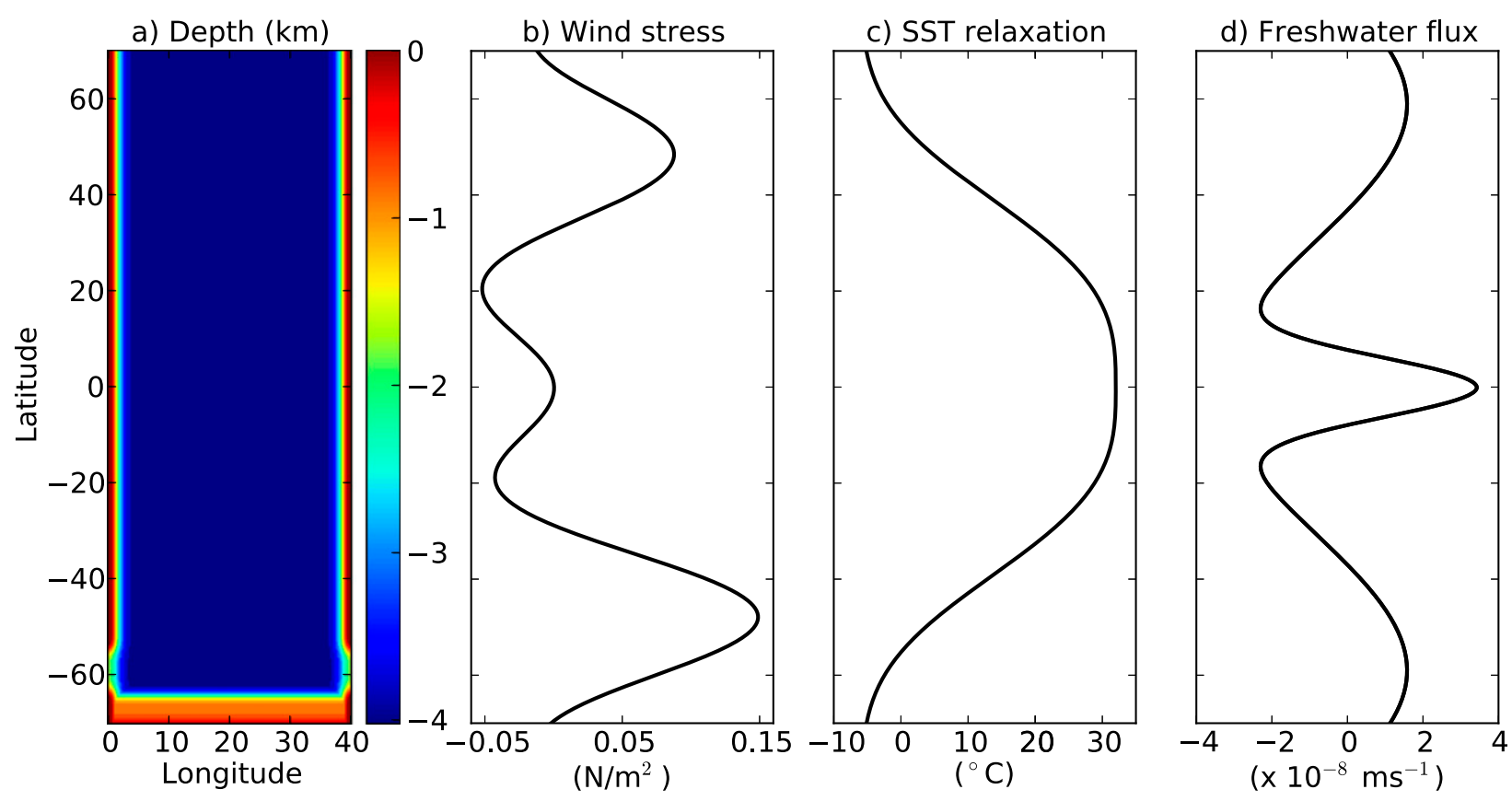

FIG. 1. (a) Model bathymetry, (b) zonal wind stress, (c) sea surface temperature relaxation, and (d) freshwater flux.

equation of state with density depending upon both temperature and salinity. The thermal expansion and haline contraction coefficients are $2 \times 10^{-4} \mathrm{~K}^{-1}$ and $7.4 \times 10^{-4} \mathrm{psu}^{-1}$, respectively. The reference case is forced by prescribed wind stress (Fig. 1b), temperature relaxation at the surface with a restoring time scale of 60 days (Fig. 1c), and a fixed freshwater flux applied as a virtual salt flux using a reference salinity of $35 \mathrm{psu}$ (Fig. 1d). The buoyancy forcing is hemispherically symmetric. All forcing is temporally invariant and zonally uniform, although variations in the model SST fields imply that atmosphere-ocean heat fluxes vary zonally and in time, even though the relaxation temperature does not. The model is run in ocean-only configuration, with no sea ice formulation. The uncoupled configuration has the advantage of higher resolution, better control over forcing perturbations, and ease of isolating the dynamical processes involved in the transient responses. The possible influence of sea ice feedbacks on the results are discussed further in section 7.

Following the $2500 \mathrm{yr}$ of spinup, a number of independent surface warming and freshwater flux perturbations are run for a duration of $100 \mathrm{yr}$. The change in Southern Ocean forcing used in the warming perturbations is shown in Fig. 2a. Except for experiment SST0.5S, we have uniformly increased the surface temperature relaxation profile by a constant amount over all latitudes (including northern latitudes, not shown). SST0.5S has enhanced warming only south of $55^{\circ} \mathrm{S}$. All of the perturbations are step changes in forcing switched on at year 0, except for SST0.5RAMP, which has the same uniformly increased SST relaxation profile as SST0.5 but is ramped linearly from $+0^{\circ}$ to $+0.5^{\circ} \mathrm{C}$ over $50 \mathrm{yr}$, starting from year 0. For the freshwater perturbations (Fig. 2b), we scale the freshwater flux by a constant factor between $50^{\circ}$ and $70^{\circ} \mathrm{S}$, decreasing to no change at $43^{\circ} \mathrm{S}$. The global freshwater flux is then recalibrated to eliminate any imbalance in the meridional integral, which has the effect of slightly reducing the freshwater input relative to the reference case north of $43^{\circ} \mathrm{S}$. After the recalibration, the freshwater flux between $50^{\circ}$ and $70^{\circ} \mathrm{S}$ has been increased by $1.15,1.3$, and 2.0 times in the perturbations labeled FW1.15, FW1.3, and FW2.0 respectively.

The state of the Southern Ocean portion of the reference case is shown in Fig. 3. The surface imprint of the stratification and the eddying nature of the model are highlighted in the snapshot of SST (Fig. 3a). The overturning circulation, shown in Fig. 3b, has been calculated on density surfaces and remapped back to depth space using the zonal and temporal mean stratification. The model reproduces three overturning cells, analogous to the observed Southern Ocean overturning cells: the surface subtropical cell, confined to the upper $300 \mathrm{~m}$ north of $50^{\circ} \mathrm{S}$; the upper, North Atlantic Deep Water cell; and the lower AABW cell, which fills the deep and abyssal layers. Consistent with observations, the abyssal cell is colder and fresher than the upper cell, despite latitudinally symmetric SST relaxation and freshwater fluxes. To compare the modeled overturning with observations of the global overturning, the transports 
a)

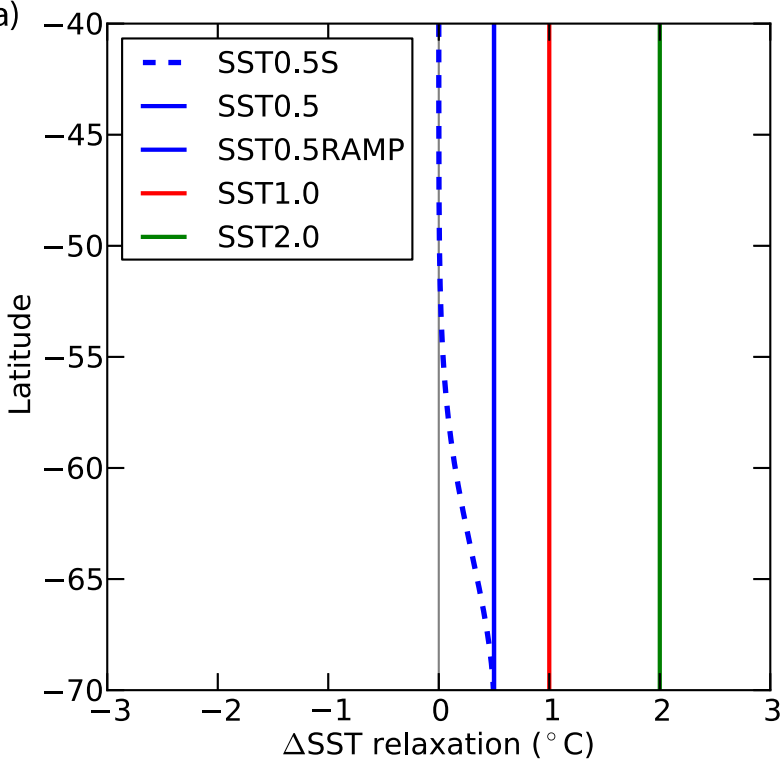

b)

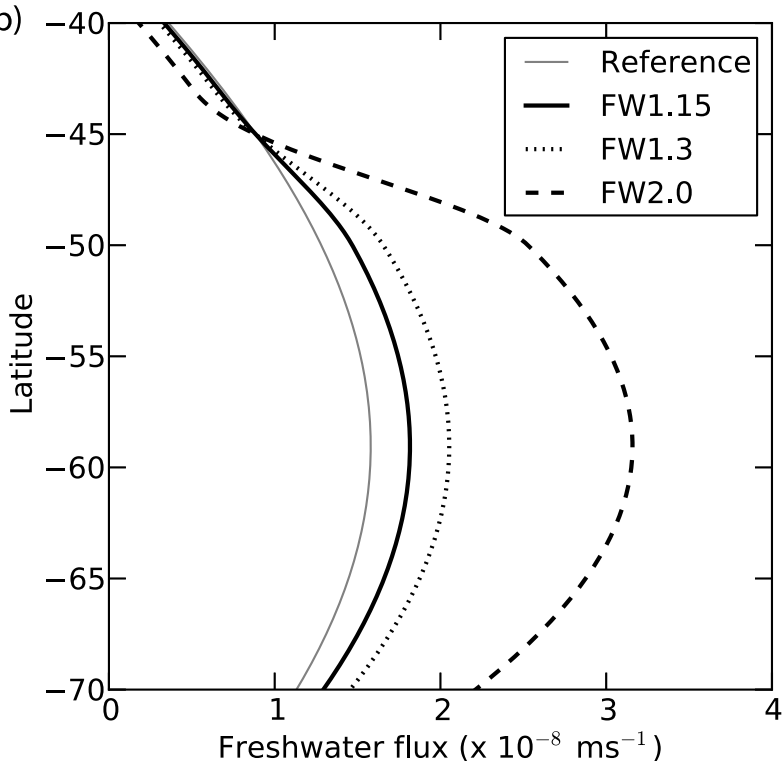

FIG. 2. Buoyancy forcing perturbations applied in the respective numerical model experiments: (a) change in SST relaxation profile for the surface warming perturbations and (b) freshwater flux perturbations (precipitation minus evaporation).

should be scaled up from the limited zonal domain by a factor (of approximately 9) to account for the width of the model domain compared to the real ocean.

\section{Surface response to buoyancy forcing perturbations}

\section{a. Freshwater perturbations}

Consistent with previous coupled model studies (e.g., Stouffer et al. 2007; Aiken and England 2008; Swingedouw et al. 2009; Menviel et al. 2010; Kirkman and Bitz 2011; Bintanja et al. 2013), the modeled upper ocean cools and freshens over the latitudes of the Antarctic Circumpolar Current in response to enhanced freshwater perturbations (Fig. 4). The region $45^{\circ}-70^{\circ} \mathrm{S}$ cools nearly uniformly, and the freshening anomaly peaks over the same latitude range. Although the region of surface cooling and freshening coincides with the spatial extent of the applied freshwater perturbation (south of $45^{\circ} \mathrm{S}$; Fig. $2 \mathrm{~b}$ ), we show in section 4 that the patterns of surface salinity and temperature anomalies are primarily determined by changes in ocean circulation, rather than the applied forcing perturbation.

As expected, the surface salinity anomaly scales with the size of the freshwater perturbation (Fig. 5b): more freshwater input results in a fresher surface layer. Interestingly, the surface cooling (Fig. 5a) scales inversely, with smaller freshwater perturbations leading ultimately to larger peak temperature anomalies (although at a slower rate). The time taken to reach the maximum cooling and freshening and a pseudo-equilibrium state also scales inversely with the magnitude of the freshwater perturbation. This temporal scaling is intuitive; for smaller perturbations it takes longer to build up a sufficiently large fresh layer at the surface before convection slows down. The dynamics setting the magnitude of the temperature and salinity anomalies, as well as the two distinct time scales of cooling and freshening, are investigated in greater detail in section 4 .

\section{b. Warming perturbations}

Despite a uniform increase in the imposed atmospheric temperature, significant surface cooling over the latitudes of the Antarctic Circumpolar Current also occurs in response to moderate warming perturbations (Fig. 5c). Similar to the freshwater perturbations, the region $45-70^{\circ} \mathrm{S}$ cools nearly uniformly. As expected, SST increases north of $40^{\circ} \mathrm{S}$ into the Northern Hemisphere (Fig. 6). There is a small region of cooling in the western half of the simulated North Atlantic basin, presumably linked to reduced Northern Hemisphere convection. However, the spatial extent and magnitude of the northern cooling trend are minimal compared with the Southern Ocean (not shown). The interhemispheric asymmetry arises as a result of the difference in the net meridional salt transport between the upper and lower overturning cells. The salinity difference between the poleward and equatorward limbs of the lower cell is much larger than for the northern upper overturning cell, resulting in a more significant salinity feedback process in the Southern Ocean than in the Northern Hemisphere (discussed further in section 4). As a result of this salinity feedback, the surface south of $45^{\circ} \mathrm{S}$ also freshens in response to the warming perturbations. The 

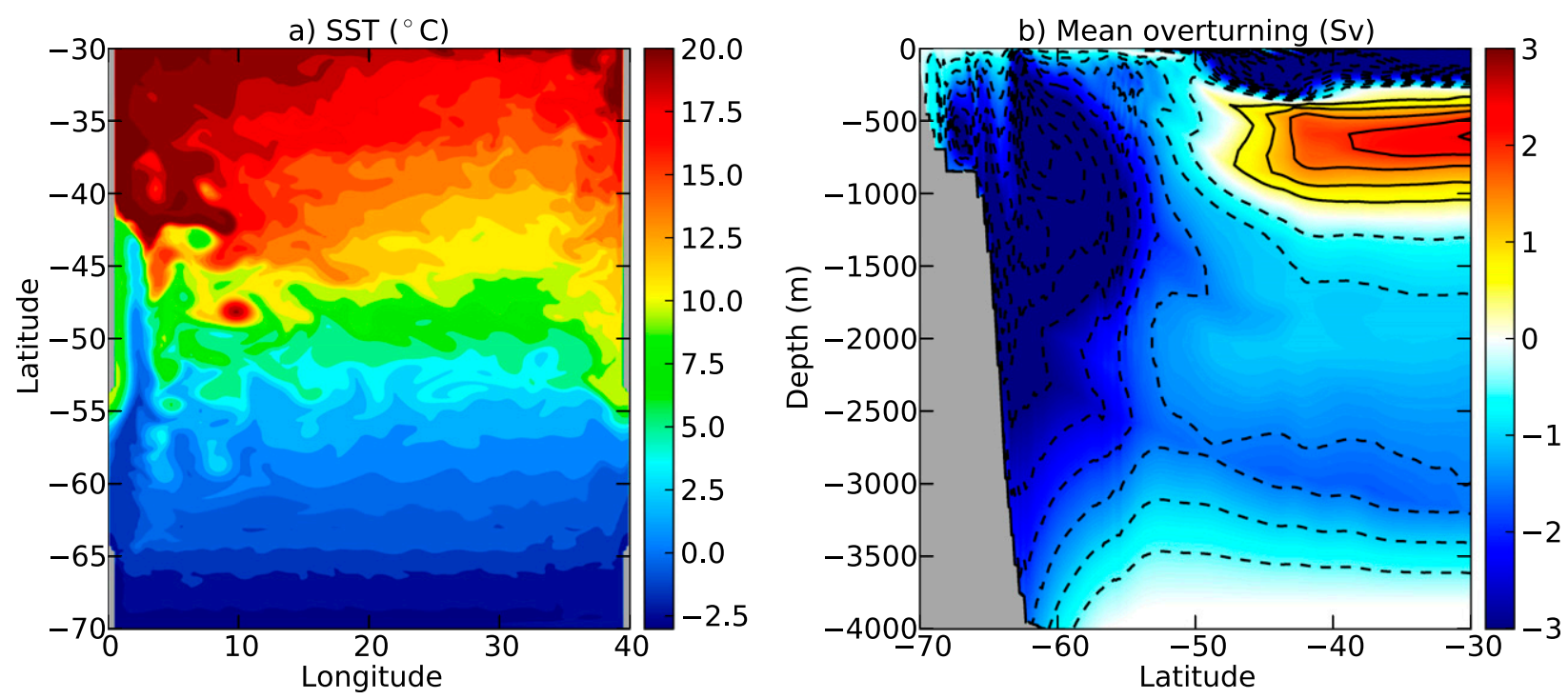

FIG. 3. Equilibrium state of the reference case. (a) Snapshot of sea surface temperature. (b) Zonal- and time-averaged overturning circulation, evaluated on density surfaces and mapped back to depth space [black lines are 0.5 -Sv contours $\left.\left(1 \mathrm{~Sv} \equiv 10^{6} \mathrm{~m}^{3} \mathrm{~s}^{-1}\right)\right]$. Red colors and solid black lines denote clockwise circulation, while blue colors and dashed black lines indicate anticlockwise circulation. Note that to compare with observations, the overturning should be scaled by a factor that accounts for the width of the model domain relative to the width of the real ocean.

freshening in the warming perturbation experiments (Fig. 5d) is comparable to that in the freshwater experiments (Fig. 5b). This comparison indicates that the dominant driver of the salinity changes in the freshwater experiments is the overturning feedback process and not the additional surface freshwater input. The surface warming experiments have a similar spatial pattern of surface cooling and freshening, independent of whether the forcing was altered locally or globally. For example, SST0.5S, which has no change in the relaxation temperature north of $55^{\circ} \mathrm{S}$, shows significant cooling trends extending to $45^{\circ} \mathrm{S}$ (although less warming north of this latitude compared with SST0.5).

As expected, the greatest warming perturbations respond with the least SST cooling, because of the additional surface heat flux input. The most extreme warming perturbation (SST2.0) has SST warming instead of cooling (Fig. 5c). In this case, the cooling feedback from the overturning shutdown is overwhelmed by the additional surface heat flux. The surface freshening is also greatest for the smallest warming perturbations. We investigate the reason for this relationship in section 4. It is worth noting here that the scaling of the salinity response for the warming perturbations is most comparable with the scaling of the temperature response for the freshwater perturbations (Figs. 5a,d), as these responses reflect the ocean feedback mechanism, rather than the direct impact of the forcing change (as for Figs. 5b,c). Variation in the location (SST0.5S) or time scale (SST0.5RAMP) of the anomalous forcing does not significantly affect the magnitude of the surface cooling or freshening, relative to a perturbation with a uniform, step change in forcing (SST0.5), provided that the forcing is sufficiently far from the threshold where SST warms rather than cools (i.e., the threshold between SST1.0 and SST2.0). As for the freshwater perturbations, the time taken to reach the quasi-equilibrium state is shorter for larger forcing changes.

\section{Heat and salt budgets}

\section{a. Methods}

The modeled cooling and freshening described in the previous section is surface enhanced and limited to the upper ocean (Fig. 6). Below the cooling region, there is a widespread warming trend to full depth in both the warming and freshwater perturbations. In this paper, we have chosen to focus predominantly on the transient surface cooling and freshening in the model, rather than the abyssal changes, because observations of surface properties are far more extensive. Therefore in this section, we analyze the heat and salt budgets for the upper 12 model levels $\left[\sim(0-180) \mathrm{m}\right.$ depth] between $60^{\circ}$ and $70^{\circ} \mathrm{S}$, as shown by the white box in Fig. 6 .

The heat budget, integrated over the subdomain, is given by

$$
\mathcal{T}=\mathcal{S}+\mathcal{A}+\mathcal{D}+\mathcal{C}
$$

where $\mathcal{T}$ is the heat content tendency, $\mathcal{S}$ is the flux through the ocean surface, $\mathcal{A}$ is the advective flux through the lateral and lower boundaries, $\mathcal{D}$ is the parameterized turbulent diffusive flux through the lower 


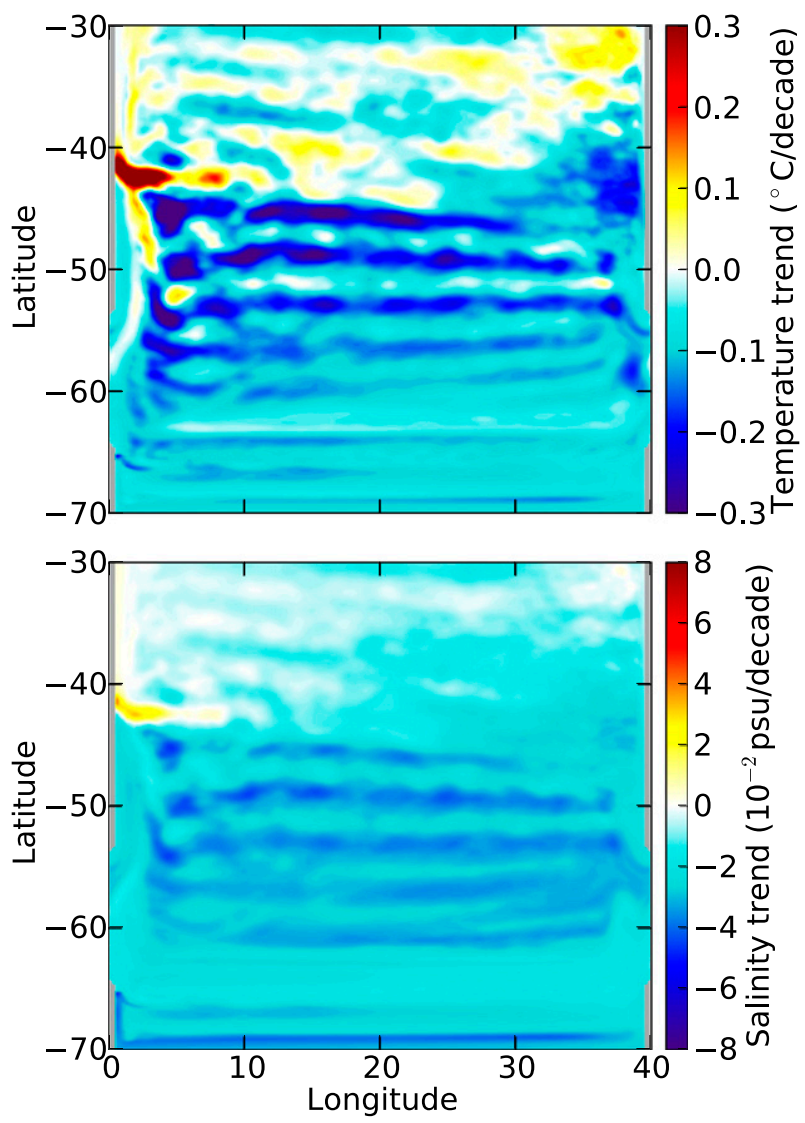

FIG. 4. Linear decadal trends in (a) sea surface temperature and (b) sea surface salinity, calculated over years $0-50$ of the freshwater perturbation FW1.15.

boundary, and $\mathcal{C}$ is the parameterized convective flux through the lower boundary. The tendency term is calculated as

$$
\mathcal{T}=\rho_{0} c_{p} \int_{-180 \mathrm{~m}}^{0 \mathrm{~m}} \int_{70^{\circ} \mathrm{S}}^{60^{\circ} \mathrm{S}} \int_{0^{\circ}}^{40^{\circ}} \frac{\Delta \theta}{\Delta t} d x d y d z
$$

where $\Delta \theta$ is the change in temperature calculated over the time period $\Delta t=1 \mathrm{yr}, \rho_{0}$ is a reference density, and $c_{p}$ is the specific heat capacity. The surface heat flux $\mathcal{S}$ varies in time, dependent on the temperature difference between the relaxation temperature profile and SST. The advective flux is the difference between the timemean fluxes through the northern and lower boundaries:

$$
\begin{aligned}
\mathcal{A}= & \rho_{0} c_{p} \int_{70^{\circ} \mathrm{S}}^{60^{\circ} \mathrm{S}} \int_{0^{\circ}}^{40^{\circ}} \overline{w_{L} \theta_{L}} d x d y \\
& -\rho_{0} c_{p} \int_{-180 \mathrm{~m}}^{0 \mathrm{~m}} \int_{0^{\circ}}^{40^{\circ}} \overline{v_{N} \theta_{N}} d x d z,
\end{aligned}
$$

where $v$ and $w$ are the meridional and vertical components of the wind velocity, the subscripts $L$ and $N$ denote evaluation at the lower and northern boundaries of the subdomain, respectively, and the overbar represents a 1 -yr time average. The diffusive flux is given by

$$
\mathcal{D}=-\rho_{0} c_{p} \int_{70^{\circ} \mathrm{S}}^{60^{\circ} \mathrm{S}} \int_{0^{\circ}}^{40^{\circ}} \kappa_{v} \frac{\overline{\partial \theta}}{\partial z} d x d y
$$

evaluated at the lower surface of the subdomain and where $\kappa_{v}$ is the vertical diffusivity. The meridional diffusion through the northern boundary is negligible.

The salinity budget is identical to the heat budget, but with specific heat content $\rho_{0} c_{p} \theta$ replaced by salt content $\rho_{0} S$, where $S$ is the salinity. Unlike the surface heat flux, the surface salt flux is temporally invariant.

The heat and salt fluxes for the reference simulation, normalized by the surface area of the subdomain, are shown from years -10 to 0 of Fig. 7. As the system is in a long-term equilibrium, the heat and salt content tendencies (black lines) are negligible. In the reference case, the cooling and freshening inputs from the surface forcing (blue lines) are largely balanced by the parameterized convective fluxes (green lines), which mix the cool, fresh surface waters with the lower, relatively warm, salty water masses. The remainder of the surface fluxes are balanced at equilibrium by the advective fluxes (red lines), through the lower and northern boundaries. Although the location of the overturning cells when averaged in density space (Fig. 3b) suggests that the advective fluxes south of $60^{\circ} \mathrm{S}$ should be entirely because of the lower overturning cell, the picture is very different in the depth space framework we have used for the heat and salt budget analysis. Figure 8 compares the location and strength of the overturning cells in the region surrounding the subdomain of interest, calculated using density layer and depth level frameworks. In depth space, the magnitude and extent of the lower overturning cell is greatly diminished, and the Deacon cell is the dominant feature (Döös and Webb 1994). In this study, we are primarily interested in determining the cause of the surface cooling and freshening; therefore, it is logical to use a depth space framework for the problem. However, the use of a depth space framework means that there is a more complicated relationship between the advective volume flux through the subdomain and the magnitude of the density-averaged overturning than would be the case in an isopycnal framework. We explicitly examine the changes in the lower overturning cell transport in section 5. The advective flux for the reference case, analyzed in the depth space framework, contributes a positive flux (i.e., warming and increasing salinity) to the subdomain because of the upwelling of relatively warmer and saltier water masses, which are modified by cooling and 
a) SST response to FW perturbations

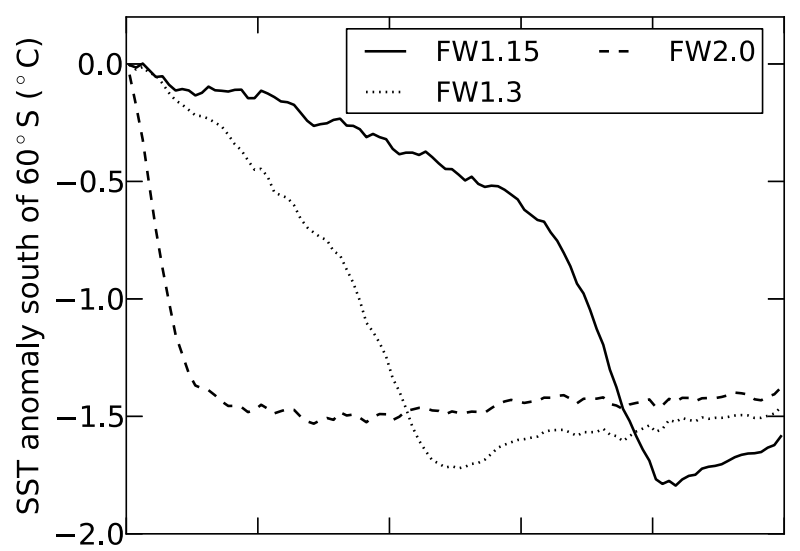

b) SSS response to FW perturbations

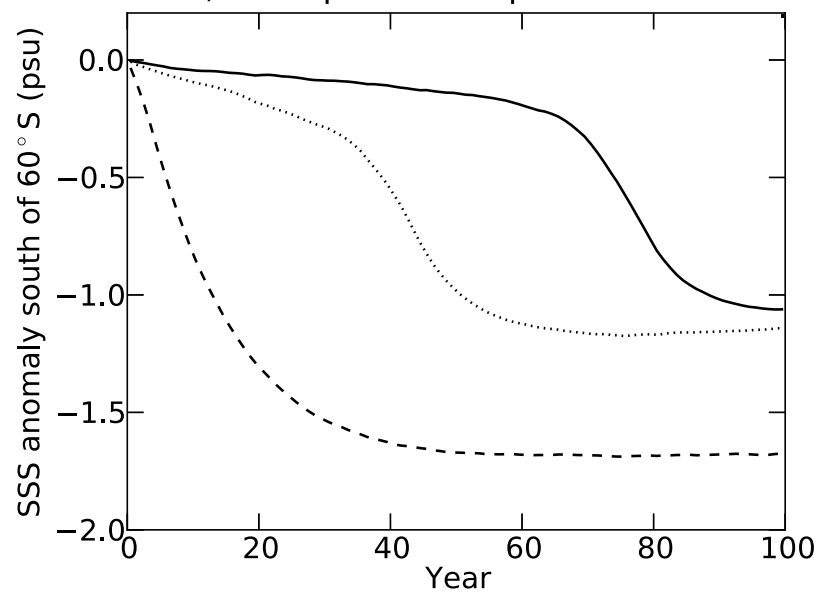

c) SST response to warming perturbations

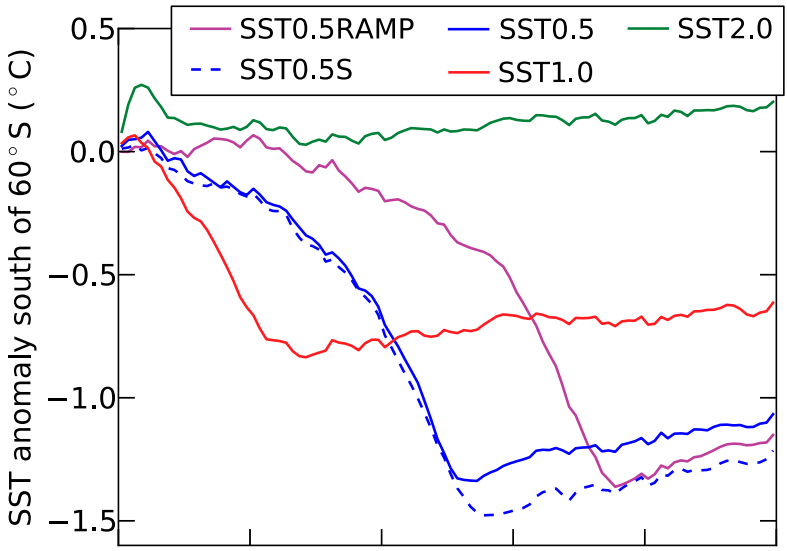

d) SSS response to warming perturbations

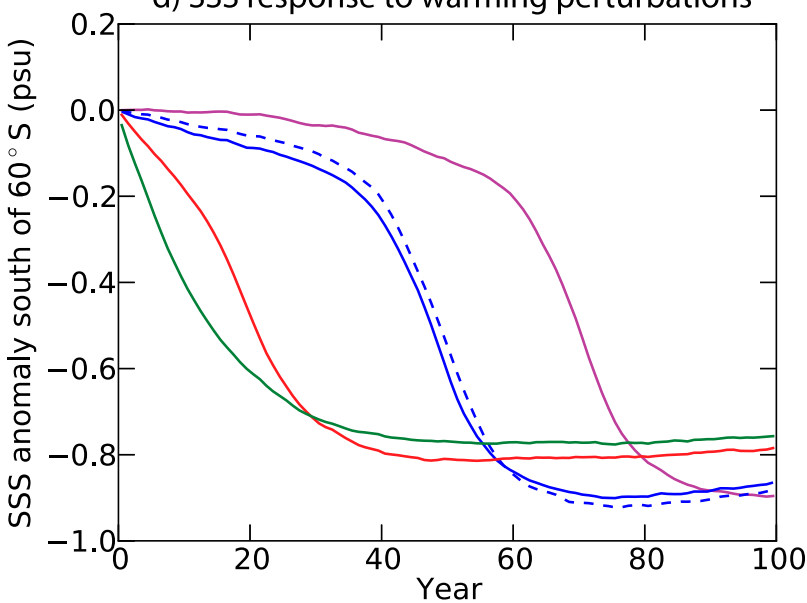

FIG. 5. Time series of (top) SST and (bottom) SSS anomalies, relative to the reference case, for the different (left) freshwater and (right) warming perturbations averaged over the region south of $60^{\circ} \mathrm{S}$.

freshening inputs at the surface before exiting the domain through the northern boundary or the southern part of the lower boundary (Fig. 8b).

\section{b. Freshwater perturbations}

In this section, we describe the evolution of the heat and salt fluxes for the perturbation FW1.15, as shown in Fig. 7, which leads to the changes in SST and SSS shown in Fig. 5 (solid lines). The shutdown of convection does not begin immediately following the perturbation but is instead dependent on a slow preceding adjustment of temperature and salinity by the advective fluxes. The transient surface cooling occurs in two distinct dynamical regimes, as separated by the dashed vertical lines in Fig. 7.

The first dynamical regime spans years $0-65$ and is dominated by decreasing advective fluxes. This time period corresponds to the initial slower rate of cooling and freshening (solid lines in Figs. 5a,b). The sudden increase in applied surface freshwater flux at year
0 induces an immediate freshening response at the surface and a subsequent small increase in the convective salt flux over the first decade as a result of the enhanced salinity difference between the surface and deep waters. However, the dominant effect of the surface freshening over years $0-65$ is a reduction in the overturning circulation and the advective volume fluxes through the subdomain. Figure 9 shows that the lower cell overturning, averaged over years 20-30 of perturbation FW1.15 and in a depth space framework, is significantly diminished compared with the reference case overturning shown in Fig. 8b. The depth-averaged "lower cell" decreases while the Deacon cell remains unchanged. The decreased volume flux slows the advective heat and salt transports to the surface, resulting in sustained cooling and freshening trends during years $0-65$. Lower SST increases the surface heat flux (i.e., there is less surface cooling; Fig. 7a) because of the interactive surface boundary condition. This SST response results in a positive feedback; whereby the increased surface 


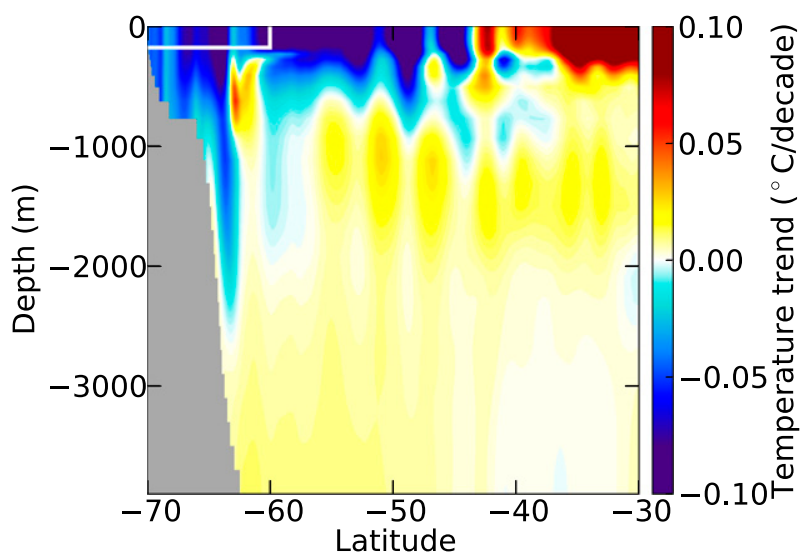

FIG. 6. The zonally averaged, linear decadal temperature trend calculated over years $0-50$ of the warming perturbation SST0.5RAMP relative to the reference case. The white box in the upper left shows the region used for the heat and salt budgets in section 4.

heat flux further reduces advection, causing more surface cooling and thereby further increased surface heat flux. The convective heat and salt fluxes remain approximately constant during this period because of the opposing effects of cooling and freshening on the surface density. Roughly half of the net cooling in the shutdown process occurs during this advection-dominated regime (years 0-65; Fig. 5a).

Convection shuts down during the second regime, between years 65 and 83 . As found in other simulations of AABW slowdown (e.g., Kirkman and Bitz 2011; Martin et al. 2013), at some point salinity changes have a greater effect on surface density than temperature changes, causing surface density to decrease and convection to slow. In our model, the nature of the surface boundary conditions contribute to the dominance of salinity changes over temperature changes; the surface heat flux increases as convection shuts down, while the surface salt flux remains constant, resulting in a greater imbalance in the salinity budget. Decreasing convection has the same effect on SST and SSS as the advection changes in regime I, but at a much faster rate. The upper ocean becomes isolated from the deep ocean, and the vertical gradients of temperature and salinity increase, which allows diffusion to increase and provide an upward flux of heat and salt.

After convection has shut down, from year 83 onward, the system is in a quasi-equilibrium, in which diffusion approximately balances the surface fluxes.

Similar transient responses of the heat and salt fluxes occur for different freshwater perturbations. The time scale of regime I (the period of advection-induced surface cooling) scales inversely with the magnitude of the freshwater perturbation. That is, smaller increases in surface freshwater flux result in slower rates of advective overturning decrease. The time scale of the convection shutdown in regime II is similar for all perturbations. The increased time scale of regime I for small perturbations explains the larger magnitude of cooling seen in these experiments (Fig. 5a). For extreme freshwater perturbations, such as experiment FW2.0, the initial change in surface salinity is sufficient to begin shutdown of convection without the prior advective feedback process, and regime II begins immediately following the perturbation. The magnitude of the surface salinity
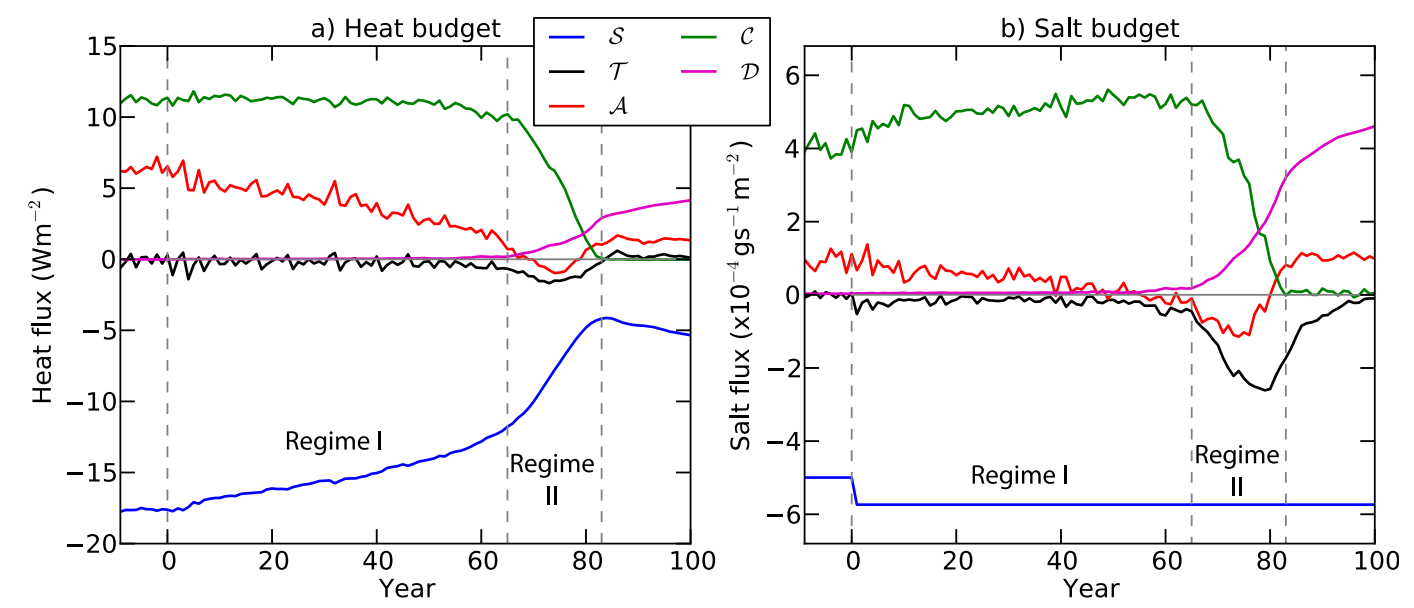

FIG. 7. Temporal evolution of the (a) heat and (b) salt budgets for the freshwater perturbation FW1.15, calculated over the subdomain of the white box in Fig. 6 and annually averaged. The terms are the surface flux $\mathcal{S}$, heat or salt content tendency $\mathcal{T}$, advective flux $\mathcal{A}$, convective flux $\mathcal{C}$, and the diffusive flux $\mathcal{D}$. The years from -10 to 0 are the reference case, and the years from 0 to 100 are the perturbation. Positive heat fluxes warm the region, while positive salt fluxes increase the salinity. 

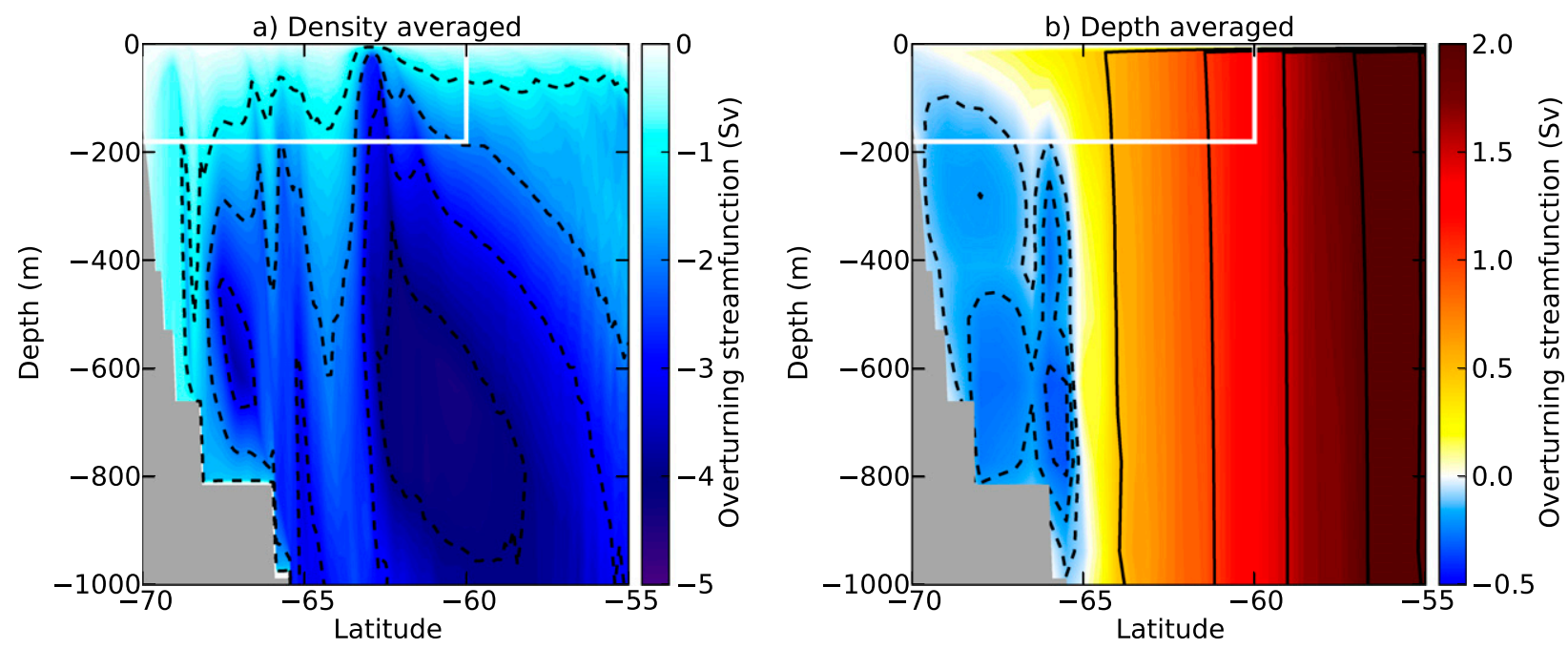

FIG. 8. The zonally averaged overturning streamfunction near the analysis region (subdomain shown by white box) for a 10-yr mean of the reference case. (a) Averaged on density surfaces (then mapped back into depth coordinates), with 1-Sv contour intervals. (b) Averaged on depth levels, with 0.1-Sv contour intervals for negative streamfunction values, and 0.5-Sv contours for positive streamfunction values. Red colors and solid black lines denote clockwise circulation, while blue colors and dashed black lines indicate anticlockwise circulation.

anomaly increases with the size of the freshwater forcing perturbation because of the direct effect of the change in surface salt flux.

\section{c. Warming perturbations}

Figure 10 shows the response of the heat and salt fluxes to the warming perturbation SST0.5. The same two distinct surface cooling regimes, as described for the freshwater perturbation in Fig. 7, are easily identifiable: the first dominated by changes in the advective fluxes and the second by the shutdown of convection.

The one notable difference compared with the freshwater perturbations is an initial period of surface warming during years $0-5$ before the cooling begins (seen in Fig. 5c). The sudden increase of the relaxation temperature by $0.5^{\circ} \mathrm{C}$ at year 0 increases the surface heat flux. Within the first $5 \mathrm{yr}$, the advective and convective heat fluxes do not adjust quickly enough to balance the change in surface input, which results in a warming at the surface, shown more clearly in Fig. 11. The increase in SST reduces the surface density and hence the convective fluxes during the first $5 \mathrm{yr}$. The surface freshwater input remains fixed, and therefore the reduced convective salt flux results in a freshening trend during the first $5 \mathrm{yr}$.

From year 5 onward in the warming perturbation, the response of the heat and salt fluxes follows a similar sequence to that described for the freshwater perturbation. The reduction in surface heat flux and subsequent surface freshening reduces the overturning circulation and advective volume flux through the subdomain. As for the freshwater perturbation, the temperature and salinity changes during the advection-dominated regime largely compensate. It is shown more clearly in Fig. 11 that the surface properties evolve parallel to a density contour in temperature and salinity space during regime I (years 537). Once convection begins to shut down around year 37 in the SST0.5 perturbation, the surface freshening dominates over the cooling signal, and the surface density rapidly reduces.

Similar to the freshwater perturbations, the time scale of the advection-dominated regime I scales inversely

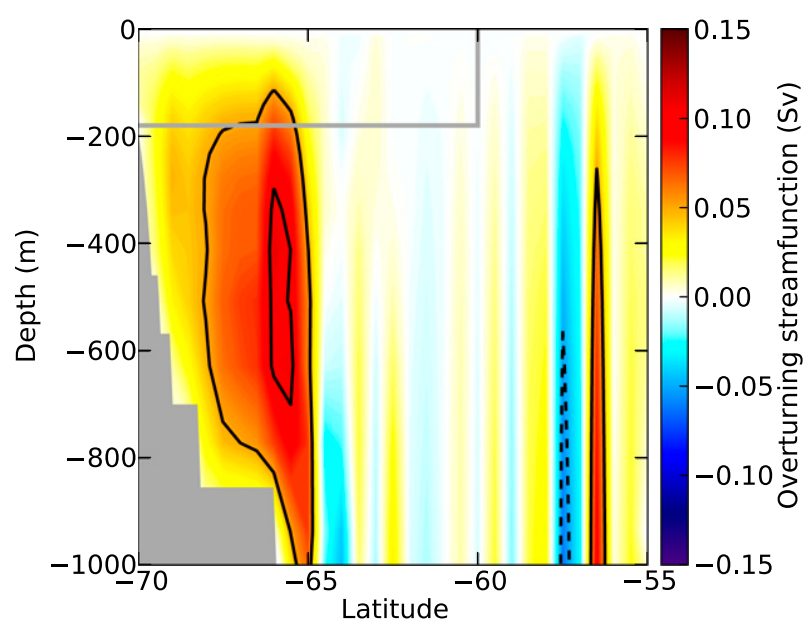

FIG. 9. The change in the zonally averaged overturning streamfunction averaged over years $20-30$ of the freshwater perturbation FW1.15 (relative to the reference case shown in Fig. 8b). Black contours show 0.05 -Sv intervals, and red colors indicate clockwise circulation. 

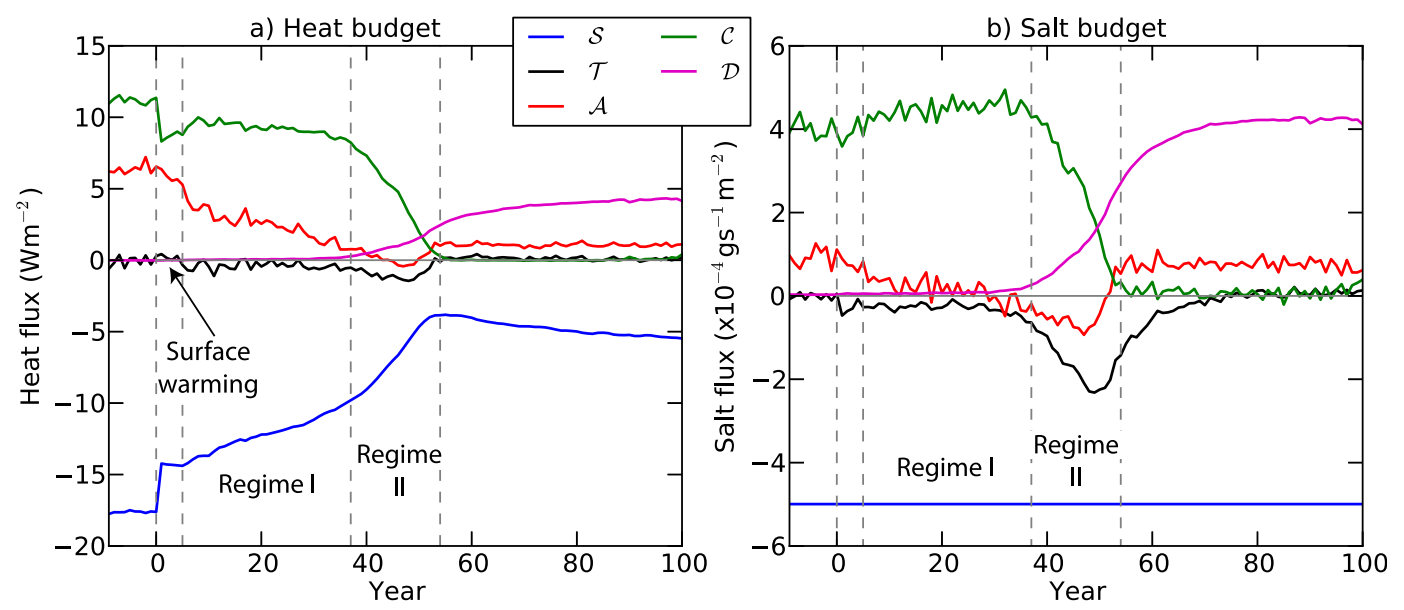

FIG. 10. As in Fig. 7, but for the warming perturbation SST0.5.

with the size of the perturbation. This is apparent by comparing the years where the slope steepens in Fig. $5 \mathrm{~d}$ for each warming perturbation. The magnitude of surface freshening scales with the length of the advectioninduced cooling period. That is, smaller changes in surface relaxation temperature result in larger maximum surface freshening anomalies because of the extended period of advective feedback. The SST cooling magnitude is largely controlled by the direct impact of the change in surface heat flux resulting from the forcing change. Large increases in surface flux, such as perturbation SST2.0, have a sufficiently large initial change in surface heat flux to begin the shutdown of convection without the prior advective feedback process, and regime II begins immediately following the initial surface warming. In the largest warming perturbation, SST2.0, the surface heat flux also switches from negative to positive, and thus no surface cooling occurs.

\section{Response of the lower overturning cell}

\section{a. Overturning transport}

The lower overturning cell shuts down in all of the warming (Fig. 12a) and freshwater perturbations. The transport at $60^{\circ} \mathrm{S}$, close to the formation region, decreases approximately linearly throughout the period when surface temperatures are cooling (Fig. 5c). The time scale for the shutdown is the same as the cooling time scale; that is, the lower overturning cell persists longer for smaller warming and freshening perturbations. Figure 13 shows the link between the lower cell transport and the sum of the advective and convective heat fluxes for the warming perturbation SST0.5. Within the initial surface warming period, there is a significant decrease in the convective heat flux by the end of the first year. The lower cell transport at $60^{\circ} \mathrm{S}$ responds with a small delay, decreasing by roughly one-third over years $1-5$. During the first cooling regime, when the heat budget is dominated by advective changes, the lower cell transport scales linearly with the advective heat flux, indicating that the advective heat flux is primarily controlled by the volume flux in the lower cell, rather than the upper overturning cell or temperature changes. The sudden change in the convective heat flux beginning at year 37 of the perturbation SST0.5 (see black circle in Fig. 13 between regimes I and II) occurs too rapidly for the lower overturning cell transport to respond within

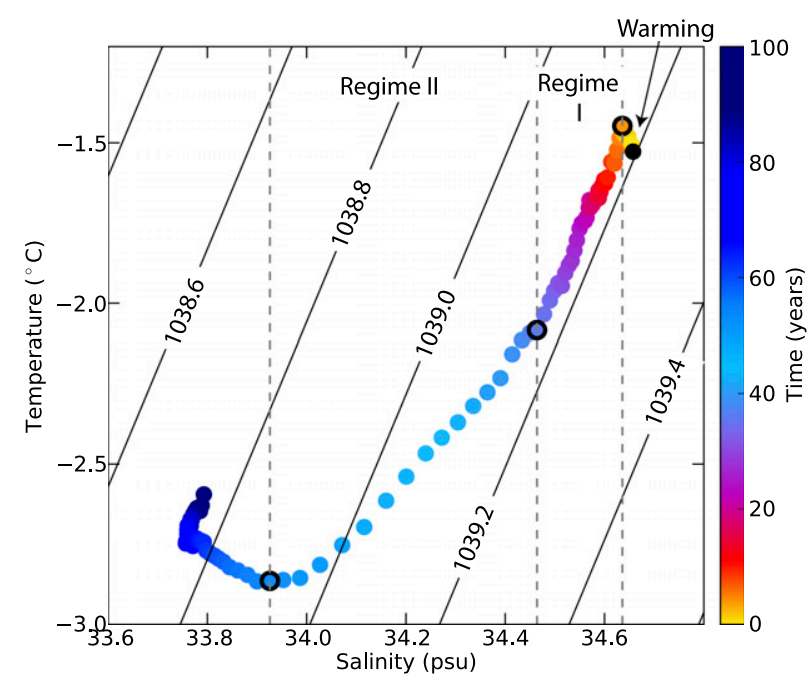

FIG. 11. Temporal evolution of SST and SSS averaged over the region $60^{\circ}-70^{\circ} \mathrm{S}$, for the warming perturbation SST0.5. Each dot represents a 1-yr time average, and colors show the temporal evolution. The black dot is the time-mean of the reference case, and dots with black outlines highlight the duration of the different cooling regimes (years 5, 37, and 54). Density contours $\left(\mathrm{kg} \mathrm{m}^{-3}\right)$ are shown by the diagonal black lines. 

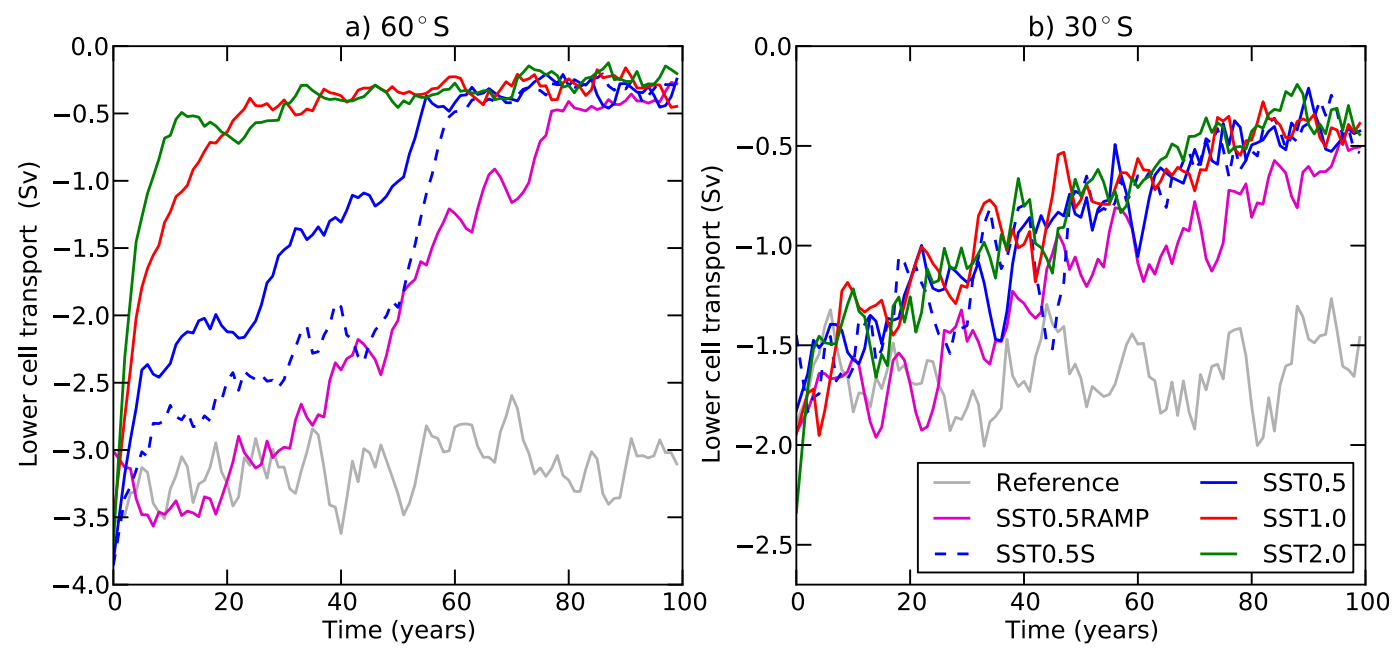

FIG. 12. Time series of the lower cell streamfunction minimum at (a) $60^{\circ} \mathrm{S}$ and (b) $30^{\circ} \mathrm{S}$ for the reference case and warming perturbations. The data has been smoothed using a 4-yr window to remove higher-frequency $(1-2 \mathrm{yr})$ variability.

the same time frame. There is a delay of around $10 \mathrm{yr}$ before the overturning transport adjusts to the decrease in the convective fluxes. The other warming and freshening perturbations have similar dynamics to SST0.5.

Despite the variation between perturbations in formation rates and the lower cell shutdown time scale at $60^{\circ} \mathrm{S}$ (Fig. 12a), the sensitivity of the lower cell transport response at $30^{\circ} \mathrm{S}$ is surprisingly independent of the perturbation magnitude (Fig. 12b). With the exception of experiment SST0.5RAMP, in all of the warming perturbations, the transport in the lower cell reaches $50 \%$ of the reference value at $30^{\circ} \mathrm{S}$ during years $45-55$, despite vastly different formation rates farther south. The slower rate of decrease in SST0.5RAMP occurs as a result of the extended length of the initial surface warming regime in this perturbation. Surface temperatures in SST0.5RAMP do not begin to cool (Fig. 5c), and the lower cell transport at $60^{\circ} \mathrm{S}$ is not distinguishable from the reference case (Fig. 12a) until around year 25. However, once the lower cell transport at $30^{\circ} \mathrm{S}$ begins to respond to the changing surface conditions, the rate of decrease in SST0.5RAMP is similar to that of the larger warming perturbations. The same insensitivity of the rate of lower cell transport decrease at $30^{\circ} \mathrm{S}$ to the perturbation magnitude is observed in the freshwater experiments. The rate of decrease of the abyssal overturning transport is essentially decoupled from the two distinct time scales of surface cooling and freshening.

\section{b. Abyssal temperature and salinity}

Figure 14 compares the evolution of abyssal temperature and salinity between a warming and a freshwater perturbation averaged below $3000 \mathrm{~m}$ and over the region $50^{\circ}-70^{\circ} \mathrm{S}$. The magnitude and direction of the trends during the advective-dominated regime I are strongly dependent on the type of buoyancy forcing perturbation. Initially, the abyssal water mass freshens in the freshwater perturbation FW1.15, with minimal temperature change until regime II (marked by the black circle in Fig. 14). In the warming perturbation SST0.5, the abyssal water mass warms and becomes saltier. From the beginning of regime II, when the convective fluxes shut down, the response is similar for both the warming and freshwater perturbations, with significant warming and increasing salinity.

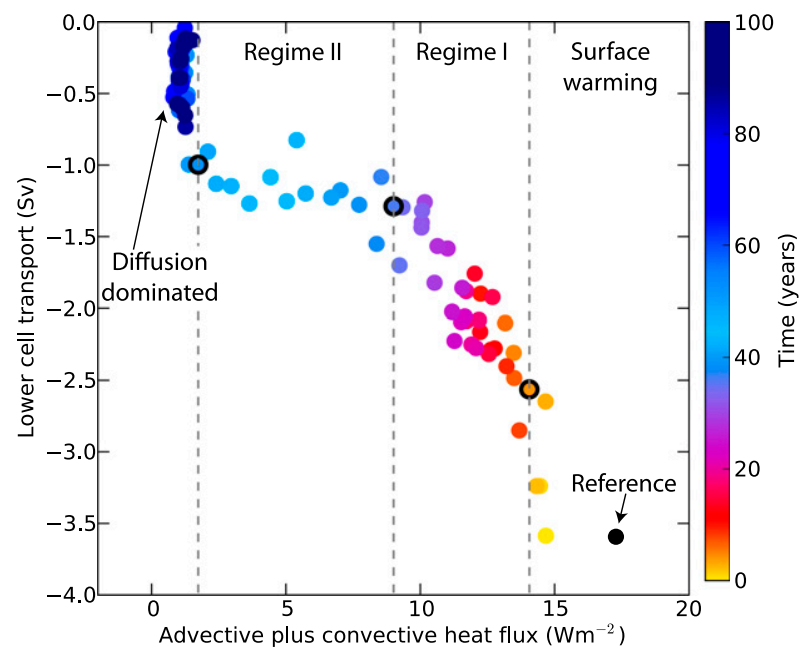

FIG. 13. Relationship between lower cell transport at $60^{\circ} \mathrm{S}$ and the sum of the advective and convective heat flux into the subdomain for the warming perturbation SST0.5. Each dot represents a 1-yr time average and colors show the temporal evolution. The black dot is the time mean of the reference case and dots with black outlines show years 5, 37, and 54 (i.e., dividing the different regimes). 


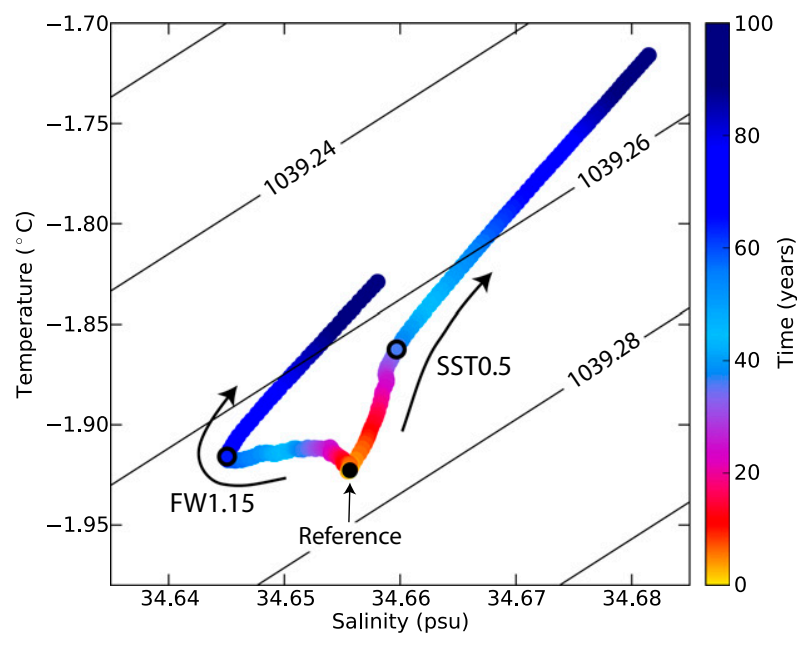

FIG. 14. Temporal evolution of abyssal temperature and salinity relative to the reference case, averaged below $3000 \mathrm{~m}$ over the region $50^{\circ}-70^{\circ} \mathrm{S}$ for the warming perturbation SST0.5 and freshwater perturbation FW1.15. The colors show the temporal evolution and the black dot is the time mean of the reference case. The black circles show the division between the advective- and convective-dominated phases, corresponding to year 37 for the perturbation SST0.5 and year 65 for FW1.15. Density contours $\left(\mathrm{kg} \mathrm{m}^{-3}\right)$ are shown by the diagonal black lines.

Unlike the nearly identical surface response for both the warming and freshwater perturbations, the temperature and salinity changes in the abyssal ocean are qualitatively different during the first part of the overturning shutdown process.

\section{Comparison to observations}

Observations of Southern Ocean temperature and salinity at the surface (Durack and Wijffels 2010; Bintanja et al. 2013) and in the deepest ocean layers (Purkey and Johnson 2010; Kouketsu et al. 2011; Purkey and Johnson 2013) show significant decadal trends, which so far remain unexplained. The changes include freshening and cooling at the ocean surface (despite ongoing global warming), and significant warming and freshening in the abyssal ocean. In this section, we expand on the hypothesis put forward by Latif et al. (2013) and Bintanja et al. (2013) - that observed Southern Ocean surface cooling may be linked to a slowdown of the bottom water formation rate-and show that both surface and abyssal observations are broadly consistent with the mechanism examined in this study.

The magnitude and spatial coverage of observed surface temperature and salinity trends (Fig. 15) are comparable to the modeled surface trends that occur in response to an overturning shutdown (e.g., Fig. 4). The SST data in Fig. 15a is sourced from the Hadley Centre
Sea Ice and Sea Surface Temperature dataset (HadISST; Rayner et al. 2003), which incorporates satellite data, float, and ship measurements. The SST trend is calculated over the period 1982-2012 in order to align with the satellite period. The observed Southern Ocean surface freshening shown in Fig. 15b is reproduced from the analysis of Durack and Wijffels (2010), which utilized salinity measurements from in situ historical archives and Argo floats over the period 1950-2008. The reader should note that the time spans analyzed for SST and SSS are overlapping but do not align. A longer time period is required for a robust salinity trend, because the salinity data coverage is so much scarcer than SST (P. Durack 2014, personal communication).

Averaged over far southern latitudes, other SST datasets show similar cooling trends to HadISST (compared in Fig. 16 and Table 1). In addition to HadISST, we have analyzed four other SST datasets: the NOAA Extended Reconstructed Sea Surface Temperature version 3b (ERSST.v3b; Smith et al. 2008), the NOAA Optimum Interpolation Sea Surface Temperature version 2 (OISSTv2; Reynolds et al. 2002), and the Japan Meteorological Agency Centennial in situ ObservationBased Estimates (COBE; Ishii et al. 2005). Of these, only HadISST and OISSTv2 incorporate satellite data in addition to in situ data derived from float and ship measurements. Other than HadSST3, all of the datasets are interpolated and use sea ice concentration to calculate SST near sea ice using statistical relationships. HadSST3 is uninterpolated but contains bias adjustment to reduce the effect of spurious trends because of changes in measurement practices. For the time series of SST shown in Fig. 16, each data point represents a 1-yr time-mean and spatial average over all available data in the region south of $50^{\circ} \mathrm{S}$. The large offset in mean temperature between the datasets arises from variation in interpolation methods, bias adjustment, and treatment of sea ice, as well as spatial and temporal gaps in the data. The HadSST3 dataset consists of SST anomalies from a climatological mean, so we have adjusted the HadSST3 time series by a constant offset so that it has the same mean SST as HadISST over the period 1982-2012. However, this adjustment does not affect the HadSST3 trend. All five SST datasets show a cooling trend over this period (Table 1), and the trends are robust when calculated over the region south of $50^{\circ} \mathrm{S}$ or the smaller region south of $60^{\circ} \mathrm{S}$, suggesting that the presence and treatment of sea ice, which extends to $\sim 60^{\circ} \mathrm{S}$ in winter, is not adversely affecting the data.

The SST trends in the model simulations are comparable to the observations (Table 1), with a cooling of $-0.08^{\circ} \mathrm{Cdecade}^{-1}$ in both the smallest warming 

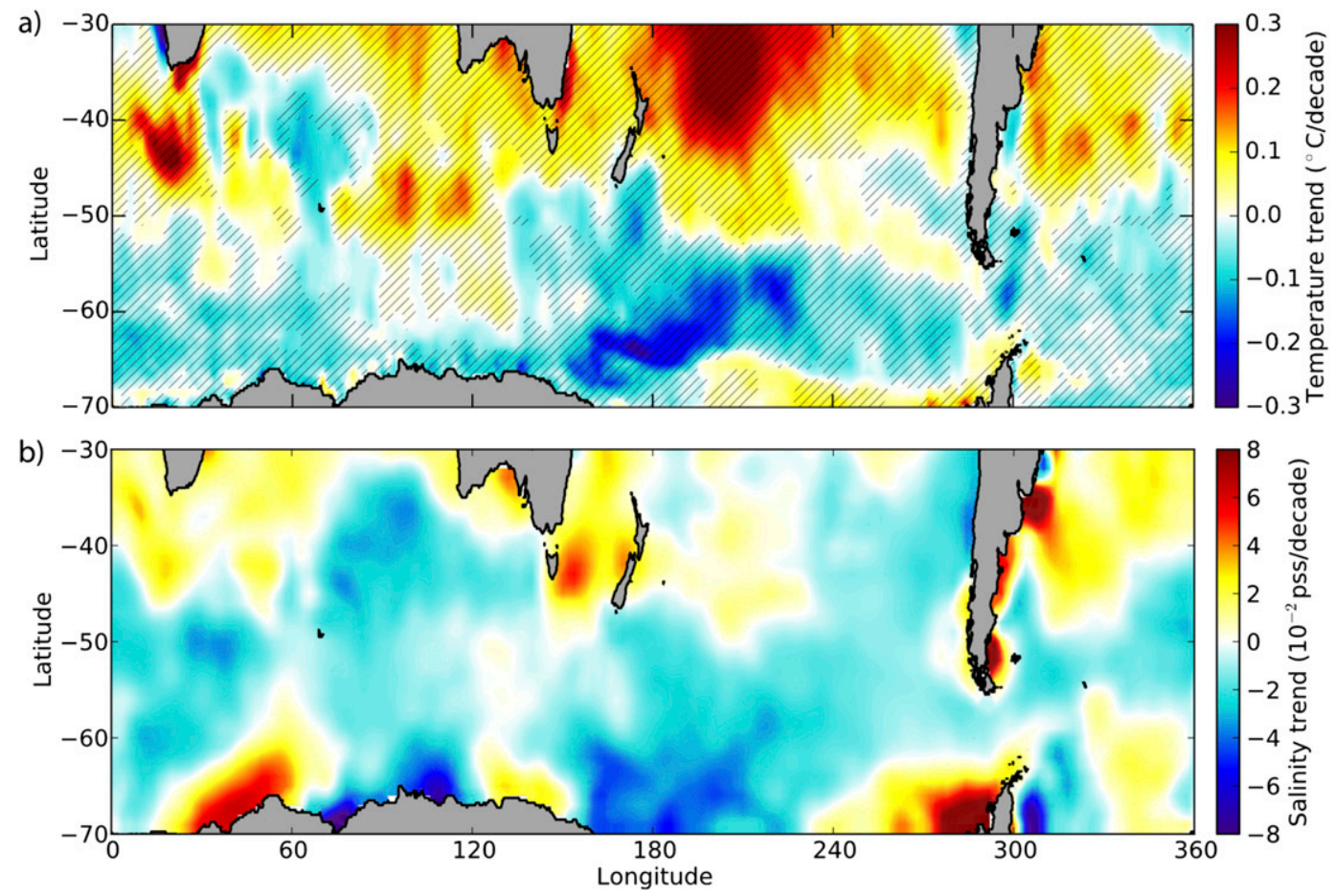

FIG. 15. Observed linear trends in Southern Ocean surface properties. (a) SST trend using HadISST calculated over the satellite period $1982-2012\left({ }^{\circ} \mathrm{C}\right.$ decade $\left.^{-1}\right)$. Diagonal stippling shows where three of the four other datasets (HadSST3, ERSST, OISST, and COBE) agree with the sign of the HadISST trend. (b) Salinity trend from Durack and Wijffels (2010) calculated over the period 1950-2008 (psu decade ${ }^{-1}$ ). Salinity data are much scarcer than temperature data; hence, a longer time period is used to increase the robustness of the salinity trend (P. Durack 2014, personal communication).

(SST0.5RAMP) and freshening (FW1.15) experiments, averaged south of $60^{\circ} \mathrm{S}$ and over years $0-50$. The modeled SST cooling rate of $-0.08^{\circ} \mathrm{Cdecade}^{-1}$ is relatively constant throughout the advection-dominated period (regime I). The cooling rate during regime II, when convection shuts down, is considerably larger,

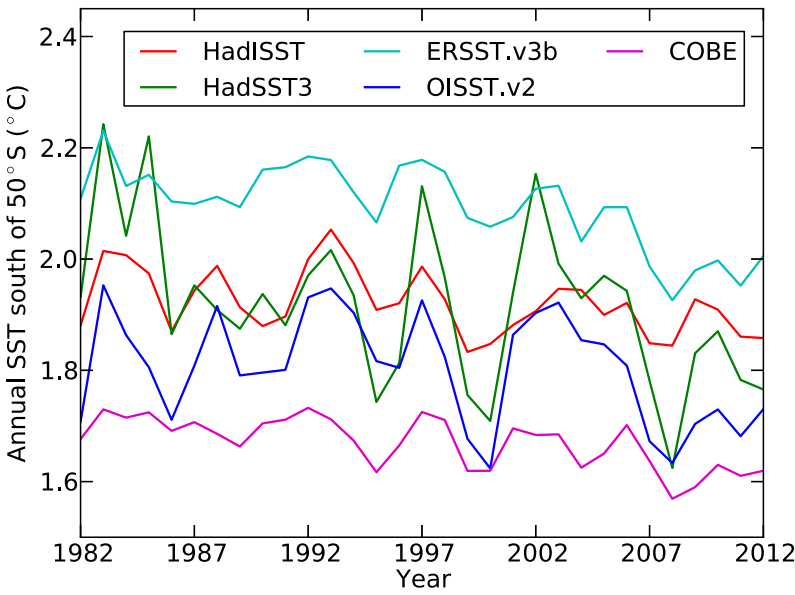

FIG. 16. Time series of annual SST for five different observational datasets, averaged over all available data south of $50^{\circ} \mathrm{S}$. The linear trends for each of the datasets are given in Table 1. around $-0.5^{\circ} \mathrm{C}$ decade $^{-1}$ in both the SST0.5RAMP and FW1.15 experiments.

The observational estimates of abyssal warming are much more uncertain than the surface trends but have been estimated as $\sim 0.03^{\circ} \mathrm{Cdecade}^{-1}$, using data from the last two decades below $4000 \mathrm{~m}$ in the Southern Ocean and south of the Sub-Antarctic Front (Purkey and Johnson 2010). The modeled abyssal warming rate in the experiment SST0.5RAMP is smaller but of the same order of magnitude as the observed trend, at around $+0.01^{\circ} \mathrm{C}$ decade ${ }^{-1}$, calculated as a linear trend over years $0-50$ of the perturbation and below $3000 \mathrm{~m}$ in the region south of $50^{\circ} \mathrm{S}$.

TABLE 1. Linear, decadal SST trends calculated over the period 1982-2012. Trends that are significantly different from zero at the $99 \%$ confidence level are shown in boldface.

\begin{tabular}{|c|c|c|}
\hline Dataset & $\begin{array}{l}\text { SST trend } 60^{\circ}-90^{\circ} \mathrm{S} \\
\left({ }^{\circ} \mathrm{C} \text { decade }{ }^{-1}\right)\end{array}$ & $\begin{array}{l}\text { SST trend } 50^{\circ}-90^{\circ} \mathrm{S} \\
\quad\left({ }^{\circ} \mathrm{C} \text { decade }^{-1}\right)\end{array}$ \\
\hline COBE & -0.02 & -0.03 \\
\hline HadISST & -0.04 & -0.03 \\
\hline OISSTv2 & -0.05 & -0.04 \\
\hline ERSST & -0.06 & -0.06 \\
\hline HadSST3 & -0.06 & -0.07 \\
\hline
\end{tabular}




\section{Discussion and summary}

We have investigated the Southern Ocean temperature and salinity changes that occur in response to surface buoyancy forcing perturbations using an eddypermitting, idealized ocean model. The mechanism proposed here relies on buoyancy-induced changes in the overturning circulation. We find that enhanced freshwater flux or, paradoxically, atmospheric warming cause a transient SST trend in the model of similar magnitude and spatial extent as the observations on a time scale of order $100 \mathrm{yr}$. The surface cooling and freshening are linked to the shutdown process of the lower overturning circulation because of the changing oceanic transport of heat and salt to the surface region.

Two distinct time scales are present in the simulations: an initially slow rate of surface cooling followed by a more rapid surface cooling. The first regime is characterized by decreasing advective heat flux to the surface, driven by a reduction in the volume transport of the lower overturning cell. In the second regime, there is a sudden drop in the convective heat flux, resulting from the surface freshwater cap set up by the preceding advective changes. The cooling and freshening is a transient effect; all of the perturbations reach a quasiequilibrium within $100 \mathrm{yr}$, in which enhanced stratification allows diffusion to balance the surface fluxes. The shutdown process and associated cooling occurs at a faster rate for larger perturbations, since the threshold for shutdown of convection is reached sooner. However, since the cooling occurs during both the advective- and convective-dominated regimes, smaller perturbations (in which the advective-dominated regime persists for an extended period) have a stronger net cooling anomaly compared with larger perturbations (in which the convective flux shutdown begins nearly immediately). The surface heat flux in the largest warming perturbation is indeed sufficient to warm, rather than cool, SST south of $50^{\circ} \mathrm{S}$, as may be expected from a simple, nondynamical view of the system.

The idealized numerical model used in this paper incorporates many simplifications in terms of topography, forcing, dense water formation processes and lack of coupling to atmosphere and sea ice, which leads to the obvious question: to what extent are the results applicable to the real climate system? In this section we address possible impacts of the idealized nature of the model and discuss some of the missing feedbacks. Despite the simplifications, this model captures relevant ocean dynamics, including the mesoscale and the ocean overturning feedback process. It would be an interesting future project to investigate whether the two time scales of advective and convective adjustment also occur in more realistic coupled models.
One of the most obvious, and perhaps consequential, modeling simplifications is the method of dense water formation in the model. In the real ocean, dense shelf waters are formed as a result of atmospheric cooling and brine rejection in localized polynyas, which subsequently entrain fresher surrounding waters to form AABW. We combine the net buoyancy effect of these separate dense water production and entrainment processes into the zonally averaged surface freshwater flux and temperature relaxation, which results in an abyssal water mass with similar properties to AABW but likely different sensitivity to forcing changes. The idealized buoyancy fluxes are also temporally invariant with no seasonal cycle. In the real ocean, the intense buoyancy fluxes that lead to convective onset are intermittent in both space and time, leading to a density profile that appears stable in a long time average, but which has transient unstable events, most notably wintertime convective overturn. In our model, the lack of seasonally varying surface forcing means that our density profile is, in some regions, always marginally unstable. However, the results of a high-resolution polynya modeling study by Marsland et al. (2007) found that dense water production responds at least qualitatively similarly to that in our idealized model. Using a coupled ocean and sea ice model with realistic topography and forcing, Marsland et al. (2007) found a $40 \%$ decrease in dense shelf water production in response to $\mathrm{a}+2^{\circ} \mathrm{C}$ atmospheric warming and a $33 \%$ reduction following a $20 \mathrm{~cm} \mathrm{yr}^{-1}$ increase in precipitation.

The other major simplification commonly used for modeling the lower overturning cell is the use of parameterized convection, which enables the transport of dense waters from the upper ocean formation regions to the lower layers (Send and Marshall 1995). In our model this is achieved by enhancing vertical mixing of temperature and salinity. Parameterized convection results in an artificial separation of the advective and convective fluxes; in the real ocean, these are both parts of the same overturning circulation cell and are codependent. However, given that a resolution of order $3-5 \mathrm{~km}$ is needed to resolve the downslope AABW pathways in $z$-coordinate models (Winton et al. 1998), which is approximately one to two orders of magnitude higher than the resolution of present climate models, it remains a worthwhile exercise to improve understanding of the dynamical processes associated with parameterized convection.

The formation of dense water and its sensitivity to forcing perturbations is also likely to be greatly affected by the use of a linear equation of state in the model. Along with missing water mass formation due to cabbeling and thermobaric processes (Klocker and McDougall 2010), 
salinity is of relatively greater importance for determining density at cold temperatures. These nonlinear processes could alter the timing of the convection shutdown at the start of regime II. In particular, as convection begins to shut down at the point where the impact of the salinity anomaly on density dominates over the impact of the temperature anomaly, it is possible that in a setup using a full equation of state, the convection may be more sensitive to forcing changes.

With no sea ice model, it is possible that we may be neglecting an important feedback process in the formation of dense water. Aiken and England (2008), in a coupled ocean-atmosphere-sea ice model, investigated a negative feedback process, whereby a decrease in convection reduced the upward heat flux and cooled SST, resulting in a higher rate of sea ice formation and therefore an increase in brine rejection and at least a partial offset in the original convective decrease. This negative sea ice feedback implies that there may be a forcing perturbation threshold below which the lower overturning cell is stable to small perturbations. Observations show that Southern Ocean sea ice extent is increasing (Parkinson and Cavalieri 2012), and one hypothesis is that the increase in sea ice may be caused by enhanced freshwater input from Antarctic ice shelf melt and a subsequent increase in vertical ocean stability (Bintanja et al. 2013). The inclusion of a sea ice model may thus partially damp the advective salinity feedback mechanism presented here.

Despite the possible impact of the simplified dense water formation in the idealized model, it is worth noting that the modeled SST cooling is also strongly dependent on the larger-scale dynamical ocean feedback and, in particular, the dynamics of the advective fluxes. In the Southern Ocean, the mesoscale eddy field has a significant effect on the circulation and advection of tracers, which means we are most likely modeling this part of the system more accurately than previous studies.

We have investigated the ocean dynamical controls on the time scale and magnitude of Southern Ocean temperature and salinity trends associated with a modulation of the lower overturning cell transport. Small surface buoyancy perturbations lead to a slow advective feedback, which ultimately results in rapid convective shutdown. Surface cooling and freshening and abyssal warming occur during the initial slow advective adjustment phase at a similar rate to presently observed trends. In summary, we have shown that both small atmospheric warming anomalies (say, because of transient greenhouse warming) and enhanced surface freshwater fluxes (because of precipitation changes and/or enhanced meltwater) can induce Southern Ocean surface cooling via a slowdown in the abyssal overturning cell. Given recent trends in radiative forcing and increased ice shelf/ice sheet melt around Antarctica, this mechanism could account for a significant component of the recent observed surface cooling and freshening south of $50^{\circ} \mathrm{S}$.

Acknowledgments. AMH was supported by Australian Research Council Future Fellowship FT120100842 and MHE by Australian Research Council Laureate Fellowship FL100100214. The analysis in section 6 is based on data made freely available by the International Argo Program and the national programs that contribute to it (http://www.argo.ucsd.edu). The Argo Program is part of the Global Ocean Observing System. The numerical model was run on the NCI National Facility in Canberra, Australia, which is supported by the Australian Commonwealth Government. We wish to thank Anand Gnanadesikan, Bob Hallberg, and three anonymous reviewers for providing useful feedback on the original manuscript, and Nicola Maher for valuable discussions regarding the observational datasets and trends.

\section{REFERENCES}

Aiken, C. M., and M. H. England, 2008: Sensitivity of the presentday climate to freshwater forcing associated with Antarctic sea ice loss. J. Climate, 21, 3936-3946, doi:10.1175/ 2007JCLI1901.1.

Bintanja, R., G. J. van Oldenborgh, S. S. Drijfhout, B. Wouters, and C. A. Katsman, 2013: Important role for ocean warming and increased ice-shelf melt in Antarctic sea-ice expansion. Nat. Geosci., 6, 376-379, doi:10.1038/ngeo1767.

Couldrey, M. P., L. Jullion, A. C. Naveira Garabato, C. Rye, L. Herráiz-Borreguero, P. J. Brown, M. P. Meredith, and K. L. Speer, 2013: Remotely induced warming of Antarctic Bottom Water in the eastern Weddell gyre. Geophys. Res. Lett., 40, 2755-2760, doi:10.1002/grl.50526.

Döös, K., and D. J. Webb, 1994: The Deacon cell and the other meridional cells of the Southern Ocean. J. Phys. Oceanogr., 24, 429-442, doi:10.1175/1520-0485(1994)024<0429: TDCATO $>2.0 . \mathrm{CO} ; 2$.

Durack, P. J., and S. E. Wijffels, 2010: Fifty-year trends in global ocean salinities and their relationship to broad-scale warming. J. Climate, 23, 4342-4362, doi:10.1175/2010JCLI3377.1.

Galbraith, E. D., and Coauthors, 2011: Climate variability and radiocarbon in the CM2Mc Earth System Model. J. Climate, 24, 4230-4254, doi:10.1175/2011JCLI3919.1.

Hogg, A. M., H. A. Dijkstra, and J. A. Saenz, 2013: The energetics of a collapsing meridional overturning circulation. J. Phys. Oceanogr., 43, 1512-1524, doi:10.1175/JPO-D-12-0212.1.

Huhn, O., M. Rhein, M. Hoppema, and S. van Heuven, 2013: Decline of deep and bottom water ventilation and slowing down of anthropogenic carbon storage in the Weddell Sea, 1984-2011. Deep-Sea Res. I, 76, 66-84, doi:10.1016/ j.dsr.2013.01.005.

Ishii, M., A. Shouji, S. Sugimoto, and T. Matsumoto, 2005: Objective analyses of sea-surface temperature and marine 
meteorological variables for the 20th century using ICOADS and the Kobe Collection. Int. J. Climatol., 25, 865-879, doi:10.1002/joc.1169.

Kirkman, C. H., and C. M. Bitz, 2011: The effect of the sea ice freshwater flux on Southern Ocean temperatures in CCSM3: Deep-ocean warming and delayed surface warming. J. Climate, 24, 2224-2237, doi:10.1175/2010JCLI3625.1.

Klocker, A., and T. J. McDougall, 2010: Influence of the nonlinear equation of state on global estimates of dianeutral advection and diffusion. J. Phys. Oceanogr., 40, 1690-1709, doi:10.1175/2010JPO4303.1.

Kouketsu, S., and Coauthors, 2011: Deep ocean heat content changes estimated from observation and reanalysis product and their influence on sea level change. J. Geophys. Res., 116, C03012, doi:10.1029/2010JC006464.

Latif, M., T. Martin, and W. Park, 2013: Southern Ocean sector centennial climate variability and recent decadal trends. J. Climate, 26, 7767-7782, doi:10.1175/JCLI-D-12-00281.1.

Manabe, S., and R. J. Stouffer, 1995: Simulation of abrupt climate change induced by freshwater input to the North Atlantic Ocean. Nature, 378, 165-167, doi:10.1038/378165a0.

Marshall, J., A. Adcroft, C. Hill, L. Perelman, and C. Heisey, 1997: A finite-volume, incompressible Navier Stokes model for studies of the ocean on parallel computers. J. Geophys. Res., 102, 5753-5766, doi:10.1029/96JC02775.

Marsland, S. J., J. A. Church, N. L. Bindoff, and G. D. Williams, 2007: Antarctic coastal polynya response to climate change. J. Geophys. Res., 112, C07009, doi:10.1029/2005JC003291.

Martin, T., W. Park, and M. Latif, 2013: Multi-centennial variability controlled by Southern Ocean convection in the Kiel Climate Model. Climate Dyn., 40, 2005-2022, doi:10.1007/ s00382-012-1586-7.

Menviel, L., A. Timmermann, O. E. Timm, and A. Mouchet, 2010: Climate and biogeochemical response to a rapid melting of the West Antarctic Ice Sheet during interglacials and implications for future climate. Paleoceanography, 25, PA4231, doi:10.1029/ 2009PA001892.

Parkinson, C. L., and D. J. Cavalieri, 2012: Antarctic sea ice variability and trends, 1979-2010. Cryosphere, 6, 871-880, doi:10.5194/tc-6-871-2012.

Purkey, S. G., and G. C. Johnson, 2010: Warming of global abyssal and deep Southern Ocean Waters between the 1990s and 2000s: Contributions to global heat and sea level rise budgets. J. Climate, 23, 6336-6351, doi:10.1175/2010JCLI3682.1.

, and - 2013: Antarctic Bottom Water warming and freshening: Contributions to sea level rise, ocean freshwater budgets, and global heat gain. J. Climate, 26, 6105-6122, doi:10.1175/JCLI-D-12-00834.1.

Rayner, N. A., D. E. Parker, E. B. Horton, C. K. Folland, L. V. Alexander, D. P. Rowell, E. C. Kent, and A. Kaplan, 2003: Global analyses of sea surface temperature, sea ice, and night marine air temperature since the late nineteenth century. J. Geophys. Res., 108, 4407, doi:10.1029/2002JD002670.

Reynolds, R. W., N. A. Rayner, T. M. Smith, D. C. Stokes, and W. Wang, 2002: An improved in situ and satellite SST analysis for climate. J. Climate, 15, 1609-1625, doi:10.1175/ 1520-0442(2002)015<1609:AIISAS > 2.0.CO;2.

Send, U., and J. Marshall, 1995: Integral effects of deep convection. J. Phys. Oceanogr., 25, 855-872, doi:10.1175/ 1520-0485(1995)025<0855:IEODC >2.0.CO;2.

Shimada, K., S. Aoki, K. I. Ohshima, and S. R. Rintoul, 2012: Influence of Ross Sea Bottom Water changes on the warming and freshening of the Antarctic Bottom Water in the Australian-Antarctic Basin. Ocean Sci., 8, 419-432, doi:10.5194/os-8-419-2012.

Sloyan, B. M., S. E. Wijffels, B. Tilbrook, K. Katsumata, A. Murata, and A. M. Macdonald, 2013: Deep ocean changes near the western boundary of the South Pacific Ocean. J. Phys. Oceanogr., 43, 2132-2141, doi:10.1175/JPO-D-12-0182.1.

Smith, T. M., R. W. Reynolds, T. C. Peterson, and J. Lawrimore, 2008: Improvements to NOAA's historical merged landocean surface temperature analysis (1880-2006). J. Climate, 21, 2283-2296, doi:10.1175/2007JCLI2100.1.

Stouffer, R. J., D. Seidov, and B. J. Haupt, 2007: Climate response to external sources of freshwater: North Atlantic versus the Southern Ocean. J. Climate, 20, 436-448, doi:10.1175/JCLI4015.1.

Swingedouw, D., T. Fichefet, H. Goosse, and M. F. Loutre, 2009: Impact of transient freshwater releases in the Southern Ocean on the AMOC and climate. Climate Dyn., 33, 365-381, doi:10.1007/s00382-008-0496-1.

Thompson, D. W. J., S. Solomon, P. J. Kushner, M. H. England, K. M. Grise, and D. J. Karoly, 2011: Signatures of the Antarctic ozone hole in Southern Hemisphere surface climate change. Nat. Geosci., 4, 741-749, doi:10.1038/ngeo1296.

van Wijk, E. M., and S. R. Rintoul, 2014: Freshening drives contraction of Antarctic Bottom Water in the Australian Antarctic Basin. Geophys. Res. Lett., 41, 1657-1664, doi:10.1002/ 2013 GL058921.

Winton, M., R. W. Hallberg, and A. Gnanadesikan, 1998: Simulation of density-driven frictional downslope flow in z-coordinate ocean models. J. Phys. Oceanogr., 28, 2163-2174, doi:10.1175/1520-0485(1998)028<2163:SODDFD>2.0.CO;2. 